\title{
See the Responsibilities of Professional News Agencies and NGOs in The Networked Digital Age Through the Xinjiang Cotton Campaign of China
}

\author{
Yun Wang, ${ }^{1, *}$
}

\author{
${ }^{1}$ King's College London, Qingdao, China. \\ "Corresponding author.Email:K19003470@kcl.ac.uk.
}

\begin{abstract}
With the dramatic development of networked digital technologies, miscellaneous applications, especially social media, have permeated all aspects of human life. The most prominent feature of social media is that the public is exploited as free labour for generating information in the emotional-oriented context, which has brought enormous challenges for professional news media and organisations. This essay draws on this feature of social media and a recent online campaign in China to argue that professional news media and organisations should take responsibility for keeping the veracity of information and sustaining the ethical value of journalism.
\end{abstract}

Keywords: Digital network, Social media, Xinjiang Cotton Campaign, power of emotion.

\section{INTRODUCTION}

After the transformation from Web 1.0 to Web 2.0, internet corporates ultimately discovered their competency and potential as platforms for usergenerated content. According to the earliest definition of Web 2.0 given by O'Reilly, Web 2.0 is "the network as platform" spanning all connected devices [1], which later systematically analysed by Manual Castells in the theory of "network society" to illustrate the evolution of the economy, politics, culture, and all other sectors of society, as well as journalism and other NGOs [2]. Moreover, Lovink concluded three distinguished features of networked media platforms: easy to use, facilitates sociality, and provides users with free publishing and production platforms that allow users to upload content in any form, be it pictures, videos, or videos or text [3]. This means social media is usercentred since low professional skills are required for publishing. A layperson could be a participator by posting texts, images and sounds, which has placed unprecedented challenges to journalism and other professional organisations since the news producers can be anyone having access to the internet, such as people in all walks of life, experts and elected politicians. Therefore, professional journalists and specialised news agencies face many crises in this networked age, such as misinformation, information overload, unemployment, and the cynicism of the audience

This article draws on the work of Ella McPherson, who has throughout studied the challenges of human rights NGOs brought by the advanced ICTs; and the study of Charlie Becket and Mark Deuze, who emphasised the power of emotion in contemporary journalism, to analyse the two prominent responsibilities of professional news media and NGOs in the networked digital age: 1) providing high-quality and trustable information to overcome the exploitative nature of social media; and 2) utilising the power of emotion rationally and appropriately to sustain the ethical value of journalism. A recent digital campaign will exemplify the whole essay in China called the Xinjiang Cotton Campaign, aiming to boycott western brands that accused cotton production in China's Xinjiang province of forced labour and other human rights abuses against Uighurs.

\section{KEEP THE VERACITY OF INFORMATION TO CONQUER THE EXPLOITATIVE NATURE OF SOCIAL MEDIA}

The nature of networked social media is exploitive since users are treated as free labour to generated content for the popularisation of platforms. Lewis Hyde 
raised the concept "gift economy" to describe people contribute or exchange products for increasing social cohesion, with no expectation of bilateral reciprocity [4]. Social media platforms were constructed based on this business model since people provide free content to gain recognition, construct communities and achieve a sense of belonging from socialisation. Platforms harness their information as the means of production and resources for the business transaction. Although sometimes compelling content can benefit the producers, the payment is usually much less than its exact value. Therefore, social media users are treated as free labour to accumulate capital for the platforms, and content posted is always derived from affection. For journalism, amateurs, part-time journalists, passionate news providers and atypical reporters cannot always ensure the accuracy, authenticity, and quality of information they post on social media since the exploitative nature of social media forced them to post plenty of news a day to maintain the exposure and attention from the public. And their news resources are always professional news agencies and organisations with stable financial income competent for fact-finding.

This exploitive nature of networked social media can lead to information crises. The overloaded information from countless sources of information leaves people unsure of whom to trust. When confusion turns to distrust, people begin to doubt everything on social media, called cynicism. According to Ella McPherson, although ICTs (Information and Communication Technologies) have primarily facilitated the fact-finding and advocacy for human right campaign, the risks are even more significant. For instance, the deception risks brought by diversified sources and widely accessible digital technologies have already become the central interference in digital fact-finding and led to the followon risks to the reputation integrity of human rights practitioners and their NGOs. And for digital advocacy, she affirms the contributions of social media on amplifying messages, saving efforts on dissemination and tracking engagements. However, the nonnegligible risks lie in the higher possibility of mistakes causing damage to reputation, credibility and professionalism, and the waste of time and money [5]. These concerns have already been proved by the recent Xinjiang Cotton Campaigns provoked by BCI (Better Cotton Initiatives), a global not-for-profit organisation working for sustainable and high-quality cotton production. BCI invited another NGO named Verite located in the US to investigate if there are risks of forced labour in the cotton production of Xinjiang Uighur Autonomous Region (XUAR) of China. However, due to the travelling restrictions and national policies in Xinjiang, the sub-organisation of Verité in China did not do any rigorous field research. Driven by subjective impressions, they purposefully identified the existence of forced labour in Xinjiang based on several publicly available information online without any local investigations [6]. They misunderstood the re-education schools and local aid-to-the-poor policies as concentration camps and national statements of forced labour. The report provided to BCI went viral immediately with the dissemination of all other news agencies. Consequently, it triggered a worldwide boycott of Xinjiang cotton leading by abundant western clothing brands like Nike, Adidas and H\&M. These brands issued statement letters on their official websites to accuse the human rights violation in Xinjiang cotton production and later caused a massive stir in China. Many professional news media like BBC also participate in the campaign and stand with BCI. This unsubstantiated drama was quickly discredited by onthe-ground reports of Chinese professional news media like People's Daily and CCTV News, and the reputation and credibility of Western news organisations and human rights NGOs drastically plummeted.

From the academic perspective, the failure of BCI, Verit é and $\mathrm{BBC}$ in the Xinjiang Cotton Campaign reminds the professional NGOs and news agencies that the cornucopia of public information online requires rigid verification before being adopted in professional news reports. As McPherson said, much digital information from civilian witnesses is not present at the movement of production, so the journalists and investigators should not rely on their direct perceptions to verify civilian witnesses' accounts and the evidence provided by amateurs. Moreover, the manipulation and deception of news stories will inevitably damage organisations' reputations and credibility [5]. Therefore, unlike other profit-oriented but low-income news media and organisations, professional news media and NGOs should take the responsibility of providing authentic and accurate information to overcome the exploitative nature of social media platforms. As Dahlgren said, despite the elimination of the hierarchical, top-down mass communication model of journalism by networked social media, there is still need for workable criteria for distinguishing better stories from less good ones, accurate accounts from distortions, truths from falsehoods [7].

Furthermore, the professional news media need to cooperate with the peripheral so as to ensure the diversity and benign development of the news media industry. Schudson raised that the old tradition of news organisations competing against one another in order to survive is giving way to a new, more collaborative tradition. Now survival depends on cooperation-share news stories [8]. This means the contents of news are no longer the core competence of news outlets owing to the digital network. In this new context, the traditional mass media such as television and broadcasting still need to play irreplaceable roles for the news production and propagation since the comparatively stable financial resources from investments and advertisements are able 
to guarantee the standardised regular news generation, giving audiences the sense of security of news resources. Besides, membership/subscription-needed online professional news sites should also be fully developed based on the network of digital media to fight against the exploitative nature of social media and subsidized journalists to explore valuable news stories. In addition, passionate news providers and commentators on social media are still highly encouraged as the complements of professional news media to provide first-hand news materials at spots and diversify the news viewpoints. This kind of cooperation of professional news media and the public is commonly seen in the networked age, which is tremendously fruitful for the timeliness and professionalism of news production. This hybridisation of journalism in the networked age satisfies the basic news demands of society [9], guarantee the financial and emotional impetus of journalists by layering the consumption levels of news, and fulfils the advantages of digital network in crowdsourcing, which should be the ideal mode of digital journalism. Nevertheless, honestly, the acute competition on social media has been drastically squeezing the space for paid news websites and threatening the future career of professional news media and journalists. The main problem is that current social media tend to be more emotional rather than objective and neutral.

\section{SUSTAIN THE ETHICAL VALUE OF JOURNALISM TO OVERCOME THE IRRATIONAL EMOTIONAL FRAGMENTATION}

Networked social media constructed an effective media ecosystem that challenges the news industry. According to the work of Beckett and Deuze, networked social media is emotional since all the contents and services are personalised, and all the human behaviours are socialised online. Besides, there are three factors driving journalism towards using emotion as a tool: economic, technology, and a better understanding of people's behaviours [10]. This means the economic model, typically attention economy, and networked technology embedded in social media push journalism to transform from rigid and objective to emotional and inspirational in order to benefit from social media users. Moreover, the more data they get from the audience, the better they understand how to select targeted news and design more acceptable storytelling formats. However, this marketing logic of journalism in the networked age can lead to filter bubbles and echo chambers that are harmful to journalism's objectivity and neutrality. Although some scholars have argued there is no true objectivity and neutrality in journalism instead of performance and manipulation, the emotionally fragmented media ecosystem is detrimental to the critical, independent thinking of the audience. Therefore, to overcome these emotional factors of networked social media, professional news media are demanded to sustain journalism's ethical, social, and economic value [10]. This section demonstrates that the professional news media and NGOs should take advantage of the emotional power of social media to guide the audience to the newsworthy stories, but they should always persuade the public through transparency of their information rather than using the power of emotion without limits.

The power of emotion has a significant function in attracting the public's attention to the notice-worthy stories. According to the recent study of Omar AIGhazzi, the life-risking and sometimes deadly, media practices of local reporters and witnesses, as well as their emotional labour, often do not feature in the understanding of journalism when it is conceived as a purely professional discursive pursuit [11]. This means many on-the-spot journalists, especially the war correspondents and human rights reporters, have no choice to distance the emotion and become activists in the events. However, their emotional labour is always neglected by journalism studies, which has a nonnegligible influence in practical dissemination and promotion. People treat their reports as first-hand descriptions which are more reliable and inspirational than any other representations and comments of other media. Besides, social media as a perfect stage of public interaction pave the way for many stylish and emotional journalist to express their personal opinions, which are not suitable for mass media. For example, in the Xinjiang Cotton Campaign, slogans launched by many professional news media like CCTV News and People's Daily on Weibo are very eye-catching to inspire the spirit of their audience. Many slogans like "Chinese market is big but does not welcome any malevolent victims", "China is open and above-board, Chinese people are friendly, but the public opinion of China must not be bullied or violated", "Our Xinjiang should not be slandered" effectively won the support of Chinese people and finally lifted the campaign into an online nationalist event, which strengthened people's national identity and built a strong sense of belonging to the country [12]. Therefore, the emotional power carried by news reports themselves has been significantly reinforced by the natural emotional context of social media, which can effectively help the professional news media to get attention from the public to news worth reading. However, the emotional power of social media should not be over abused.

The emotional power of social media can bring the post-truth society if it is intentionally over abused by news media. The news stories from atypical labours, commentators and influencers usually carry intensive personal value orientation since they want to inspire the agreement and following of the public, which can help them be more influential and make profits by selling advertisements later. These emotionally guided news 
stories always contain exaggerated facts, intentionally selected words, and even misinformation, aiming to select followers with the same emotional attitude and identities, especially young people who are the most active groups on social media. As Dahlgren said, the key activities of young people are socialising-spending time with other online who in some way are a part of one's social circles. But in using such sites as Facebook and MySpace, or even in diary blogging about their lives, they are not only socialising but also affirming and confirming their identities [7]. Their identities will then be constantly reinforced with the help of personalisation and customisation of social media algorisms. The emotional fragmentation under the intentional guidance of news media and social media can lead to a post-truth society in the long run, which means people would believe whatever they want to believe rather than the truth proved by evidence. Consequently, the public can lose independent and critical thinking ability, and the rational discussion environment expected by Habermas's "public sphere" would finally become a bubble in the age of social media [13]. For instance, the American news media themselves are polarised, and according to the statistics, people who support the conservative party $(47 \%$ of the entire population) prefer to read Fox News; CNN, MSNBS, NPR; and NYT are the news sources of the people advocating the liberals. People then can hardly see and be persuaded by oppositional views, and society is going to the post-truth stage when emotions, preferences, and personal beliefs become the criteria for judging facts.

In the Xinjiang Cotton Campaign, the conflict between western countries and China is not only about whether there are forced labours in cotton production, but also between different ideologies. Those who disagree with Chinese ideology attack Chinese politics on social media platforms with what they believe to be strong evidence, while Chinese who love their country are actively led by domestic media to blame foreign media and brands for slanders. The focus of the conflict has gone beyond human rights to an ideological conflict. Western people who trust the media tend to believe that there are human rights problems in countries different from their ideology. Their belief is based not on evidence, but emotion. Therefore, in order to avoid the emotional power of social media being exploited by conspiracy theories and demagoguery, it is incumbent on the news media and NGOs to do their utmost to improve the transparency of the evidence to avoid conflicts beyond the event. As Beckett \& Deuze said, a way to put emotion front and centre in today's networked journalism in a principled and professional manner is through transparency. It has the potential to prevent the pitfall of journalism of emotion from being accused of simple subjectivity and bias [10].

\section{CONCLUSION}

This article argues that professional news media and organisations have irreplaceable responsibilities to ensure that information sources are true and accurate, and to maintain a rational information environment in the contemporary networked media age since the exploitive nature of social media and its emotional oriented communication environment can lead to severe information crises and fragmented unhealthy news context. As a counterexample to the failure of professional media to fulfil these two responsibilities, the recent Xinjiang Cotton Campaign warns that all news organisations should learn from the loss of trust and the removal of credibility of $\mathrm{BCI}$ and $\mathrm{BBC}$. Although social media's embedded exploitative nature and emotional power can be quite challenging for news agencies to survive without any compromises, they should find effective solutions to overcome the challenges brought by the new media environment and take responsibility in the network society. As Deuze said, there is a core to the profession that continually reflects on itself vis-à-vis the development in and challenges of the periphery in that would represent a continuous circling of the wagons to keep truly original, edgy, pioneering, creative, non-formulaic, nontraditional ways of news gathering, storytelling, and audience engagement at the perimeter.

Some suggestions are given for these two challenges. On the one hand, the professional news media should transfer the core into investigation and verification of digital evidence with the cooperation of distinctive news media and agencies to overcome the exploitative nature of social media. On the other hand, the professional should embrace the emotional characteristic of networked social media to make people more engaging when reading the news stories but still need to keep an effective distance to ensure its status and reliability. The transparency of information should be considered as the most effective solution to all crises and risks. Hopefully, this article can contribute some inspirational thinking to the professional news media and organisations in surviving in the networked digital media society.

\section{REFERENCES}

[1] O'Reilly, T., Web 2.0: Compact definition, O'Reilly Media 1 October, 2005, Available at (blog): http://radar.oreilly.com/2005/10/web-20-compactdefinition.html (Accessed on: 01/08/2021)

[2] Castells, M., The Rise of the Network Society: The Information Age, Economy, Society and Culture, John Wiley \& Sons, Incorporated, Hoboken, 2009.

[3] Lovink, G., Networks without a cause: A critique of social media, Cambridge: Polity Press, 2011. 
[4] Sundararajan, A., Chapter 1: The Sharing Economy, Market Economies, and Gift Economies. In The Sharing Economy: The End of Employment and the Rise of Crowd-Based Capitalism, London: MIT Press, 2016, pp.23-46.

[5] McPherson, E., Social Media and Human Rights Advocacy' in Tumber, H. and Waisbord, S. (eds) The Routledge Companion to Media and Human Rights, London, UK: Routledge, 2017, pp. 279-288.

[6] Liu, X. \& Fan, LZ, Western concocted "Xinjiang forced labour", got it!, Global Times, 2021. Available at (blogs): https://new.qq.com/rain/a/20210804A0281Y00 (Accessed on 10/08/2021)

[7] Dahlgren, P., Chapter 8: Online Practices and Civic Cultures, in Media and political engagement: Citizens, communication, and democracy, Cambridge: Cambridge University Press, 2009, pp. 172-181.

[8] Schudson, M., Chapter 12: The first news revolution of the twenty-first century, The sociology of news, New York: Norton Publishers, 2011, pp. 205-230.

[9] Chadwick, A., The hybrid media system: Politics and power, Oxford, UK: Oxford University Press, 2013.

[10] Beckett, C. \& Deuze, M., On the Role of Emotion in the Future of Journalism, Social Media + Society, 2016, 2(3), pp.1-6. Doi:10.1177/2056305116662395.

[11] AI-Ghazzi, Omar., "Forced to report": Affective proximity and the perils of local reporting on Syria, Journalism, 2021, pp.1-15. Doi: $10.1177 / 1464884920984874$.

[12] Financial news, Do you really understand the reasons behind the \# I Support Xinjiang Cotton \#? Weibo, 2021, Available at (blog): https://weibo.com/ttarticle/p/show?id=2309404619 125434745115(Accessed 30/07/2021).

[13] Habermas, J., Lennox, S. and Lennox, F., The Public Sphere: An Encyclopedia Article, in New German Critique, Duke University Press, 1964(3), pp. 49-55. 